\title{
Ovsynch versus Ultrasynch: Reproductive efficacy of a dairy cattle synchronization protocol incorporating corpus luteum function
}

\author{
J. A. A. McArt, L. S. Caixeta, V. S. Machado, C. L. Guard, K. N. Galvao, O. G. Sá Filho, and R. C. Bicalho ${ }^{1}$ \\ Department of Population Medicine and Diagnostic Sciences, College of Veterinary Medicine, Cornell University, Ithaca, NY 14853
}

\begin{abstract}
The objective was to compare the reproductive efficacy of Ultrasynch, a synchronization program based on functionality of the corpus luteum as determined by ultrasonography, with an Ovsynch protocol. A randomized field trial was conducted on a commercial dairy in Cayuga County, New York, during scheduled weekly pregnancy examinations. Cows $(\mathrm{n}=745)$ determined nonpregnant 28 to $34 \mathrm{~d}$ after artificial insemination (AI) were randomly assigned to Ultrasynch or Ovsynch protocols. Cows assigned to the Ultrasynch management program $(\mathrm{n}=366)$ were treated based on corpus luteum (CL) diameter: cows with a CL > 23 $\mathrm{mm}$ received an injection of $\mathrm{PGF}_{2 \alpha}$ and were bred via AI following detection of estrus (Ultra-PGF), whereas cows with a $\mathrm{CL} \leq 23 \mathrm{~mm}$ received injections and were bred on an Ovsynch protocol. Cows assigned to the Ovsynch management program $(\mathrm{n}=379)$ were placed on an Ovsynch protocol regardless of CL diameter. Pregnancy status was rechecked 28 to 34 d after AI; cows determined nonpregnant after initial enrollment were maintained in their assigned management group and received treatments based on CL diameter if in the Ultrasynch group and Ovsynch treatments if in the Ovsynch group. Hazard of pregnancy was similar between Ultrasynch and Ovsynch (hazard ratio $=1.10$, $95 \%$ confidence interval $=0.88-1.36)$. Median days to conception were 98 and 87 for Ultrasynch and Ovsynch, respectively. The detection of estrus rate of cows in the Ultra-PGF group was $49 \%$; better performance of an Ultrasynch management program may be achievable in a herd with a higher rate of estrus detection.
\end{abstract}

Key words: dairy cow, reproduction, synchronization, ultrasound

\section{INTRODUCTION}

Profitability of dairy farms depends on many factors, one of which is the reproductive efficiency of dairy

Received November 20, 2009.

Accepted February 15, 2010.

${ }^{1}$ Corresponding author: rcb28@cornell.edu cows (Britt, 1985; Plaizier et al., 1997; Meadows et al., $2005)$. There is a large cost associated with the number of days open (Groenendaal et al., 2004; De Vries, 2006), and this reproductive failure is an important cause of economic loss for dairy farmers (Plaizier et al., 1997). Unfortunately, reproductive efficiency has declined for dairy cows worldwide and has been the trend for dairy fertility since 1957 (Lucy, 2007). A major component of this decline may be attributed to reduced estrus detection, anestrous, and reduced expression of estrus (Pursley et al., 1997; Lucy, 2001; Bicalho et al., 2007); these factors represent one of the major challenges in reproductive management (Lopez et al., 2004).

To reduce dependency on the detection of visible signs of estrus, ovulation synchronization protocols were developed to allow cows to be inseminated at a fixed time; the use of these protocols has become common practice in the dairy industry (Caraviello et al., 2006). The Ovsynch protocol (Pursley et al., 1995) is the most commonly used timed AI (TAI) program in dairy herds; however, treatments based on the presence or absence of a corpus luteum (CL) are still common practice (McDougall and Rhodes, 1999; McDougall, 2003; Bartolome et al., 2005). An accurate diagnosis of a CL becomes paramount for successful treatment with $\mathrm{PGF}_{2 \alpha}$, because this drug is most effective when an active CL is present. Previous research by our group showed that using a threshold diameter of $23 \mathrm{~mm}$ greatly increased accuracy of active CL detection by ultrasonography (Bicalho et al., 2008).

Conception to an Ovsynch protocol was markedly decreased during resynchronization compared with first insemination (Fricke et al., 2003) mainly because of a lack of presynchronization (Moreira et al., 2001; Galvão et al., 2007). Therefore, in herds with good detection of estrus, it is possible that selectively administering $\mathrm{PGF}_{2 \alpha}$ to cows with an active CL may result in a similar time to conception compared with enrollment of all cows to Ovsynch. Such an approach, if successful, would be economically advantageous because of a saving in hormone injection costs.

The primary objective was to compare the reproductive efficiency of Ultrasynch, an estrus synchronization program that bases hormonal treatments on the pres- 
ence or absence of an active CL, to a standard Ovsynch program.

\section{MATERIALS AND METHODS}

\section{Farm and Management}

Data were collected from a dairy farm in Cayuga County, New York, from October 6, 2008, until March 2, 2009. This farm was selected because of its longstanding relationship with Cornell University's Ambulatory and Production Medicine Clinic. The farm milked 2,750 Holstein cows 3 times daily averaging 40.9 $\pm 0.4 \mathrm{~kg}$ of milk per cow per day during the study period. Cows were housed in freestall barns with concrete stalls covered with mattresses and bedded with recycled manure solids. Cows were fed a TMR consisting of approximately $55 \%$ forage (corn silage, alfalfa and grass haylage, alfalfa silage, alfalfa hay, and wheat straw) and $45 \%$ concentrate (cornmeal, soybean meal, canola meal, cottonseed, and citrus pulp). The diet was formulated to meet or exceed the NRC (2001) requirements for lactating Holstein cows weighing $650 \mathrm{~kg}$ and producing $40 \mathrm{~kg}$ of $3.7 \% \mathrm{FCM}$.

The prestudy reproductive management used a combination of Presynch (Moreira et al., 2001), Ovsynch (Pursley et al., 1995), Resynch (Fricke et al., 2003), and detection of estrus, with 25 to $30 \%$ of cows bred via TAI and the remainder bred after detection of estrus solely by using activity monitors (Alpro, DeLaval, Kansas City, MO). Estrus detection was based on electronic activity sensors worn around the neck; no cows were AI based on visual detection of estrus. Activity sensors determined the level of activity in a cow, and the computer compared it to her rolling activity over the previous week. Cows were then classified as having an activity of $0,1,2$, or 3 and AI when they attained an activity level of 3 . Inseminations were conducted once daily. Cows bred via TAI were separated by automatic sort gates during the first milking of the day for breeding, and cows that triggered the estrus activity monitoring system were AI after the milking following detection of estrus. Veterinarians from the Cornell Ambulatory and Production Medicine Clinic administered the necessary hormone injections to cows determined nonpregnant at palpation; all other reproductive injections, as well as all AI, were executed by 3 trained farm personnel. First-service conception rate for cows during the trial was $41 \%$ based on ultrasonography at 28 to 34 d post-AI (DPAI).

\section{Data Collection and Study Design}

A randomized field trial was designed involving cows in all stages of lactation. Before the beginning of the trial, all cows were randomly assigned to 1 of 2 synchronization management groups: Ovsynch (control) and Ultrasynch (treatment). Randomization was completed in Excel (Microsoft, Redmond, WA) using the random number function and imported into the farm's Dairy Comp 305 program (Valley Agricultural Software, Tulare, CA).

During weekly pregnancy checks, cows 28 to 34 DPAI were separated from their penmates using an automatic sort gate, restrained by head locks, and examined by transrectal ultrasonography for pregnancy diagnosis and measurement of CL diameter. Ultrasonography of the CL and conceptus was performed according to Fricke (2002) and accomplished using 2 ultrasound units: an Easi-Scan portable bovine ultrasound with a $5-\mathrm{MHz}$ linear probe and $7.5 \times 10 \mathrm{~cm}$ wrist-mounted LCD display (Steuart Medical, Rochester, MN) and an Ultra Scan 50 portable front harness ultrasound with a $5-\mathrm{MHz}$ linear probe and $7 \times 10 \mathrm{~cm}$ display (Alliance Medical Inc., St. Joseph, MO). Ultrasonography was carried out by 1 of 3 trained researchers associated with the Cornell University Ambulatory and Production Medicine Clinic: a faculty member, a resident, and a postdoctoral veterinarian.

Cows determined nonpregnant at pregnancy examination were enrolled based on their previous random assignment; nonpregnant cows placed on the do-notbreed list were excluded. Cows assigned to the control group were placed on an Ovsynch protocol; an initial injection of $100 \mu \mathrm{g}$ of GnRH (Factrel, Fort Dodge Animal Health, Fort Dodge, IA) was given at pregnancy examination, followed $7 \mathrm{~d}$ later with $25 \mathrm{mg}$ of $\mathrm{PGF}_{2 \alpha}$ (Lutalyse, Pfizer, New York, NY). Forty-eight hours later, cows received a second injection of $100 \mu \mathrm{g}$ of GnRH and were AI via TAI 20 to $24 \mathrm{~h}$ later. Cows detected in estrus by the activity monitoring system were AI and removed from the TAI list. Cows determined nonpregnant after initial enrollment in the Ovsynch management group were again enrolled on an Ovsynch program.

Cows assigned to the treatment group were placed on an Ultrasynch protocol and were treated based on the largest diameter of any detectable CL: cows with CL > $23 \mathrm{~mm}$ (Ultra-PGF) were given an injection of $25 \mathrm{mg}$ of $\mathrm{PGF}_{2 \alpha}$ and $\mathrm{AI}$ following detection of estrus during the following $2 \mathrm{wk}$, and cows with CL $\leq 23 \mathrm{~mm}$ received injections and were bred on an Ovsynch protocol (Ultra-Ov). If estrus was not detected in an UltraPGF cow within $14 \mathrm{~d}$ of $\mathrm{PGF}_{2 \alpha}$ administration, the cow was examined at the following herd check and enrolled in the appropriate Ultra-PGF or Ultra-Ov group based on CL diameter. Cows determined nonpregnant after initial insemination in the Ultrasynch management group were again enrolled to the appropriate Ultra-PGF 


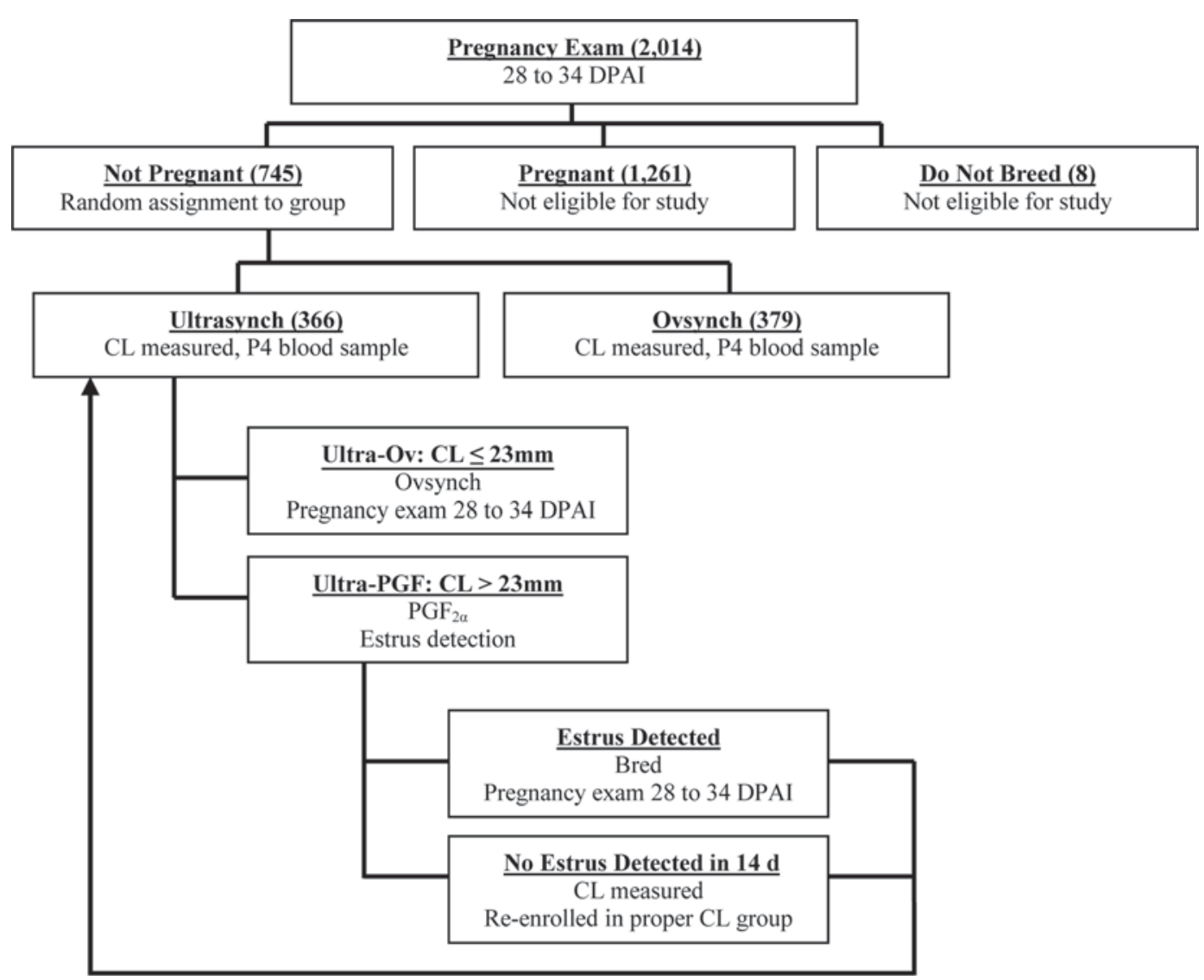

Figure 1. Flowchart showing assignment of cows to treatment groups (n), synchronization protocol, and breeding method. DPAI $=$ days post-AI; P4 = progesterone; $\mathrm{CL}=$ corpus luteum.

or Ultra-Ov group based on CL diameter. The Ultrasynch management system was specifically designed to allow cows to oscillate between Ultra-PGF or Ultra-Ov subgroups during the trial. A flowchart showing cow assignment to treatment groups is provided in Figure 1.

Additional data were collected on BCS, CL diameter, and DIM at enrollment as well as lactation number (1, 2 , or $\geq 3$ ). Group allocation, pregnancy diagnosis, and administration of injections on the day of pregnancy examination were completed by the aforementioned veterinarians, who were not blinded to group assignment. All other hormone injections, TAI, and AI following detection of estrus were performed by trained farm personnel unaware of group assignment.

Blood samples was collected from all study cows to replicate previous results associating CL diameter with blood progesterone level. Using a Vacutainer tube without anticoagulant and a 20 gauge $\times 2.54 \mathrm{~cm}$ Vacutainer needle (Becton, Dickinson and Company, Franklin Lakes, NJ), $10 \mathrm{~mL}$ of blood was collected from the coccygeal vein or artery of each cow. After collection of all blood samples on a given day, the samples were transported to the laboratory in ambient temperatures, spun in a centrifuge at $2,000 \times g$ for $15 \mathrm{~min}$ at $4^{\circ} \mathrm{C}$, and the serum was removed and frozen at $-25^{\circ} \mathrm{C}$. Circulating concentrations of progesterone were determined in 7 assays using a solid-phase radioimmunoassay kit containing antibody-coated tubes and ${ }^{125}$ I-labeled progesterone (Coat-a-Count, Diagnostic Products Corporation, Los Angeles, CA) according to the manufacturer's instructions. The assay sensitivity was $0.01 \mathrm{ng} / \mathrm{mL}$, and the mean intraassay and interassay coefficients of variation were 4.48 and $8.65 \%$, respectively.

The study aimed to enroll at least 800 cows determined nonpregnant at 28 to 34 DPAI. This sample size, assuming a desired type I error rate of $5 \%$, a power of $80 \%$, and a baseline probability of conception of 0.35 , would allow detection differences in the probability of conception between the 2 treatment groups of 0.1 . A proposal was reviewed and approved by the Cornell University Institutional Animal Care and Use Committee (\#2009-0001).

\section{Statistical Analysis}

Descriptive statistics were generated with the UNIVARIATE, MEANS, and FREQ procedures of SAS 
Table 1. Descriptive statistics $( \pm \mathrm{SE})$ of treatment groups at study enrollment; the study enrolled 379 cows in the Ovsynch group and 366 cows in the Ultrasynch group ${ }^{1}$

\begin{tabular}{lcccc}
\hline Treatment & LACT & DIM & BCS & CL $(\mathrm{cm})$ \\
\hline Ovsynch & $2.04 \pm 0.06$ & $250 \pm 4.9$ & $3.2 \pm 0.02$ & $1.85 \pm 0.07$ \\
Ultrasynch & $2.08 \pm 0.06$ & $252 \pm 5.6$ & $3.2 \pm 0.02$ & $1.84 \pm 0.07$ \\
\hline
\end{tabular}

${ }^{1}$ No difference was found between the Ovsynch and Ultrasynch group in lactation number (LACT), DIM, BCS, or corpus luteum (CL) diameter.

(SAS Inst. Inc., Cary, NC). The CL diameter at which sensitivity and specificity were optimized for ultrasonographic detection was evaluated by receiver operating characteristic (ROC) curve analysis using MedCalc version 9.2.0.1 (MedCalc Software, Mariakerke, Belgium). The ROC curve analysis plots the sensitivity against the false positive fraction $(1-$ specificity) to detect the best combination of sensitivity and specificity for all possible CL diameters. The point closest to the upper left corner of the ROC curve represents the best combination of sensitivity and specificity and is selected automatically by the MedCalc software.

The effect of treatment group on the time from enrollment to conception was analyzed by Cox's proportional hazards. The time series variable for the model was enrollment-to-conception interval or enrollment-to-censure interval. A censoring variable was used to detect cows pregnant by the end the study from those that either died (or were culled) or were simply not detected pregnant by the end of the study. The Cox's proportional hazards model was fitted using the TPHREG procedure of SAS. Furthermore, potential confounding variables (such as age, parity, milk production, season at calving, caving ease score, and others) were extracted from Dairy Comp 305 management software and offered to the model as independent variables. Variables and their respective interaction terms were considered significant when $P \leq 0.05$. Independent variables were manually removed stepwise from the model by descending order of $P$-value.

\section{RESULTS}

\section{Descriptive Statistics}

A total of 745 cows were used in the analysis, 379 in the Ovsynch and 366 in the Ultrasynch group. A cow could be enrolled multiple times if she was continuously found nonpregnant at pregnancy examination; thus, there were 1,242 total enrollments, 583 in the Ovsynch group and 660 in the Ultrasynch group. Of enrollments in the Ultrasynch group, $43 \%$ had a CL diameter $>23$ $\mathrm{mm}$ (Ultra-PGF) and $57 \%$ had a CL diameter $\leq 23 \mathrm{~mm}$ (Ultra-Ov). Descriptive measures of the 2 treatment groups concerning BCS, CL diameter, and average
DIM at enrollment as well as lactation group are in Table 1, which shows effective randomization to treatment groups.

The conception risk for each level of the variables BCS, CL size, and serum progesterone concentration did not differ between the Ultrasynch and Ovsynch groups. Additionally, differences in BCS, CL size, and serum progesterone concentration at enrollment did not have an effect on conception risk within treatment group. Detection of estrus of Ultra-PGF cows did not differ based on BCS, CL size, or serum progesterone concentration at enrollment.

\section{Detection of Estrus}

Of the 287 Ultra-PGF enrollments, 141 (49\%) were detected in estrus; distribution of days until detection of estrus from $\mathrm{PGF}_{2 \alpha}$ administration can be seen in Figure 2. Detection of estrus of Ultra-PGF enrollments did not differ based on BCS, CL size, or blood progesterone level, nor was there any difference in estrus detection based on DPAI at enrollment.

\section{Serum Progesterone Level and CL Diameter}

A ROC curve analysis was conducted on serum blood progesterone levels to verify a minimum CL diameter threshold as performed by Bicalho et al. (2008). The sensitivity and specificity of an active CL via ultrasound, identified by a concurrent serum progesterone level of $\geq 1 \mathrm{ng} / \mathrm{mL}$, was optimized using a threshold diameter of $20 \mathrm{~mm}$ (Figure 3 ).

\section{Effect of Treatment on Reproductive Performance}

A Cox's proportional hazards analysis showed that the hazard of pregnancy was similar between cows in the Ovsynch and Ultrasynch groups, with Ovsynch cows $1.10(95 \% \mathrm{CI}=0.88-1.36)$ times more likely to conceive than cows in the Ultrasynch group $(P=0.40$; Table 2). All confounding variables offered to the model were nonsignificant and excluded from the model. To control for the known effect of parity on reproductive performance, the independent variable parity number was forced into the Cox's proportional hazard model; 


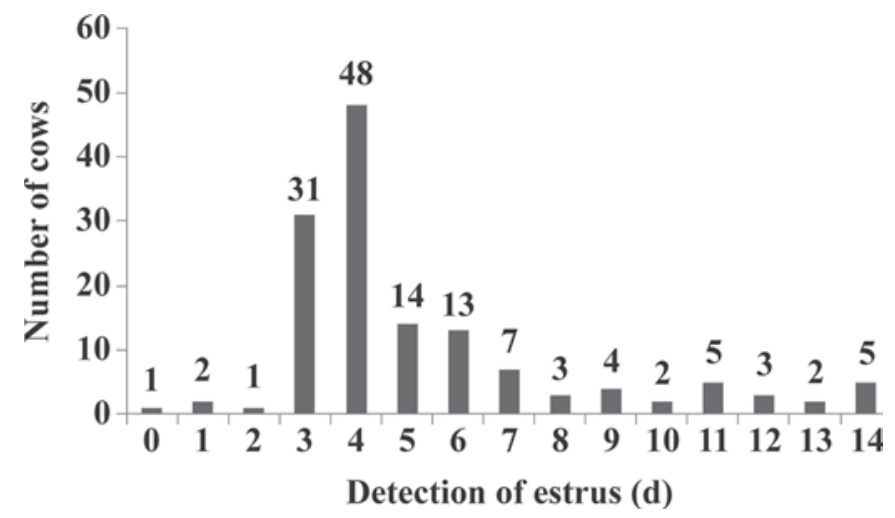

Figure 2. Histogram showing the number of days to detection of estrus post-PGF $\mathrm{PG}_{2 \alpha}$ administration of the $141(49 \%)$ Ultrasynch cows with a corpus luteum $>23 \mathrm{~mm}$ in diameter detected in estrus (Ultra$\mathrm{PGF}$ ). Maximum detection of estrus occurred at $4 \mathrm{~d}$ post-PGF $\mathrm{P}_{2 \alpha}$ with $48(34 \%)$ cows in estrus.

there was no significant difference between the 3 parity groups $(P=0.31)$.

To illustrate the hazard of pregnancy over time, a Kaplan-Meier survival curve analysis was performed. There was no difference in median days to conception between cows in the Ovsynch or Ultrasynch groups at 87 and 98 d, respectively $(P=0.40$; Figure 4$)$.

\section{DISCUSSION}

The study was conducted to determine how the reproductive efficacy of Ultrasynch, a synchronization program based on functionality of the CL, compared with that of a standard Ovsynch protocol. Analysis of the results showed no significant difference in conception rate or median days from enrollment to conception between groups.

Few studies have investigated conception after firstservice AI based on CL diameter and detection of estrus. A trial completed by Lòpez-Gatius et al. (2004) compared first- and second-service AI pregnancy rates of cows on Ovsynch with cows in specific synchronization groups (CL diameter $\geq 15 \mathrm{~mm}$, natural estrus, anovulatory follicle, and ovarian cyst). Preinsemination treatments were based on observed ovarian structures present at protocol initiation. By assigning cows to specific synchronization groups, they were successful in significantly improving pregnancy rates over the control Ovsynch group for both first-service AI and cumulative second-service AI. Yet, their study did not examine how cows in specific synchronization groups performed after multiple services, whereas the present study observed conception in cows found nonpregnant to at least one service.
Although our analysis conclusively determined there was no difference in time to conception between groups, 2 issues must be explored to account for the less-thanhypothesized conception results from the Ultrasynch group: detection of estrus and assignment to Ultrasynch subgroup based on a CL threshold diameter of $23 \mathrm{~mm}$. Cows in the Ultrasynch treatment group may not have conceived sooner than cows in the Ovsynch control group because of Ultrasynch's reliance on detection of estrus. Considering that $43 \%$ of enrollments in the treatment group were bred solely on estrus, the on-farm rate of detection of estrus played a large role in the time to conception of Ultrasynch enrollees. The study herd estrus detection rate of Ultra-PGF cows was $49 \%$, much lower than values found in other studies (Stevenson et al., 2003; Cairoli et al., 2006).

Stevenson et al. (2003) examined the effects of $\mathrm{PGF}_{2 \alpha}$ and estrus detection on cows found nonpregnant at first pregnancy examination. Cows given $\mathrm{PGF}_{2 \alpha}$ at nonpregnant diagnosis and AI after detected estrus (or 72 to 80 $\mathrm{h}$ after $\mathrm{PGF}_{2 \alpha}$ treatment if no estrus was detected) had similar conception rates compared with cows AI solely off estrus, at 22 and 23\%, respectively. Estrus, found by visual observation and tail chalk evaluation after

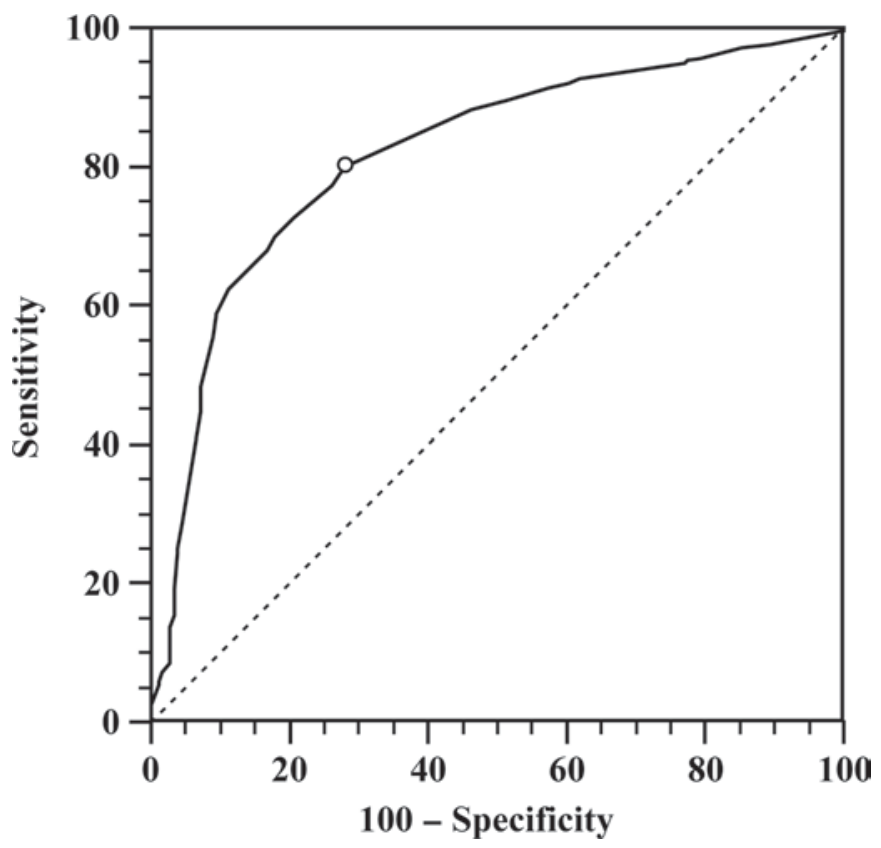

Figure 3. Receiver operating characteristic curve analysis of blood progesterone level and corpus luteum (CL) diameter of 1,242 cow enrollments after nonpregnant diagnosis at 28 to $34 \mathrm{~d}$ post-AI. The sensitivity and specificity of an active CL via ultrasound, identified by concurrent serum progesterone level of $\geq 1 \mathrm{ng} / \mathrm{mL}$, was optimized using a threshold diameter of $20 \mathrm{~mm}$ (sensitivity $=80.0$, specificity $=$ $72.0)$. The area under the curve was $0.82(95 \% \mathrm{CI}=0.80-0.84)$. 


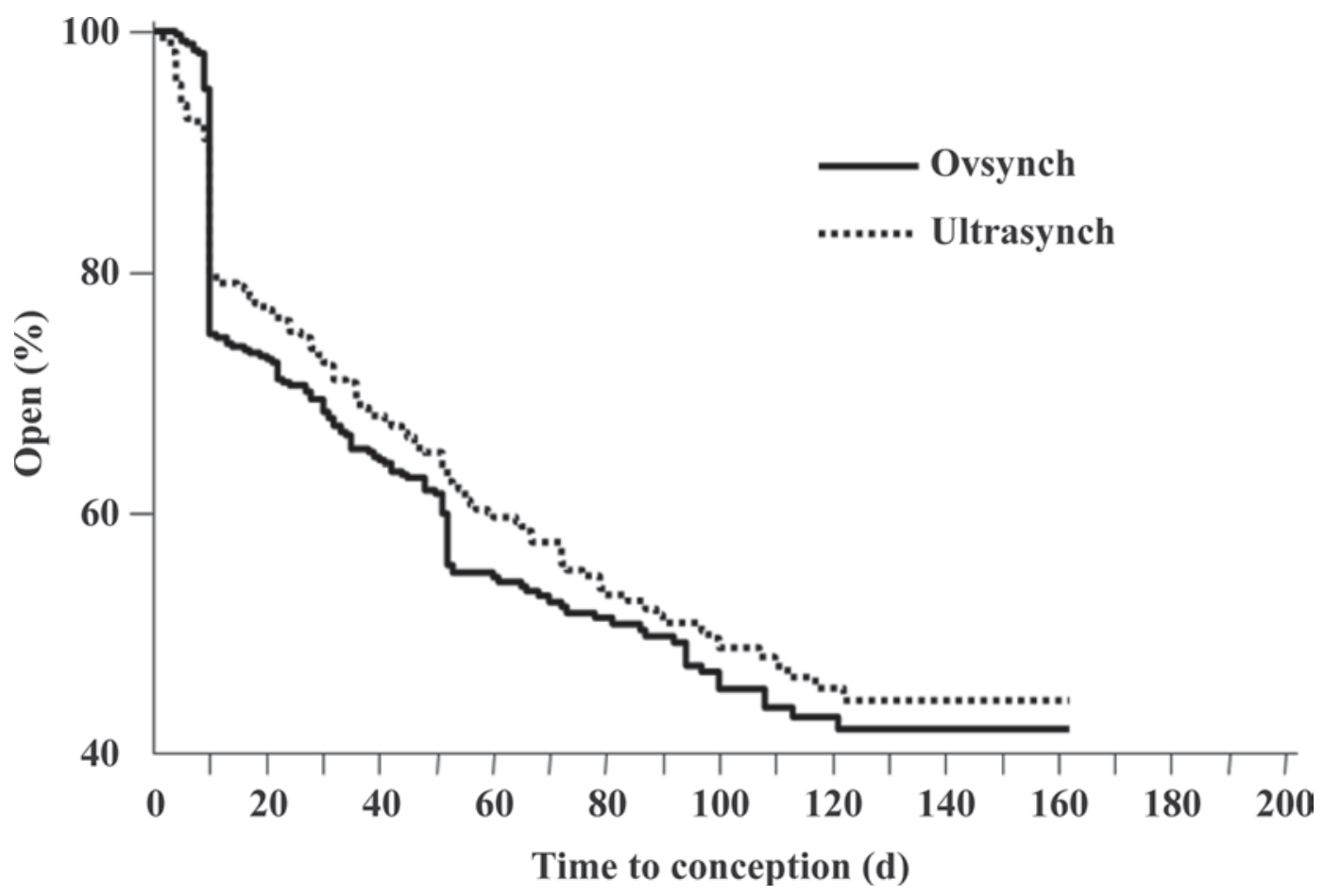

Figure 4. Kaplan-Meier survival analysis illustrating the effect of synchronization protocol on time to conception for 379 cows enrolled in Ovsynch and 366 cows enrolled in Ultrasynch. There was no difference in median days to conception between cows in the Ovsynch or Ultrasynch groups at 87 and $98 \mathrm{~d}$, respectively $(P=0.40)$.

morning milking, was detected in $75 \%$ of cows given $\mathrm{PGF}_{2 \alpha}$ at nonpregnant diagnosis. Similarly, Cairoli et al. (2006) observed estrus within $7 \mathrm{~d}$ of $\mathrm{PGF}_{2 \alpha}$ administration in $82 \%(230 / 280)$ of cows diagnosed with a CL via rectal palpation.

It is unclear why the estrus detection rate in the study was low; analysis of the herd's Dairy Comp 305 records for the 6 mo following completion of the study showed an estrus detection rate of $60 \%$, calculated by examining the number of cows found nonpregnant at pregnancy exam that did not have an estrus detection event since the previous breeding. During the trial, approximately 300 of the activity transponders were replaced because they were no longer transmitting activity data to the monitoring system. It is unknown whether the 300 cows with replaced activity transponders were enrolled, and if so, to which group they may have been assigned. This technical failure likely had an effect on the time to conception for cows in both treatment groups, especially the Ultra-PGF cows because they were being AI solely on estrus detection. Although the rate of detection of estrus was lower than that found in other studies, time to estrus detection post-PGF ${ }_{2 \alpha}$ administration was similar. In Cairoli et al. (2006), 95\% of the cows found in estrus after receiving $\mathrm{PGF}_{2 \alpha}$ were detected between 3 and 5 d post- $\mathrm{PGF}_{2 \alpha}$ administration, with the majority detected on d $4(57 \%)$. Other studies have produced supporting results (Archbald et al., 1993; Stevens et al., 1993). It is difficult to model the outcome of Ultrasynch using a higher rate of detection

Table 2. Cox's proportional hazard ratio showing the effect of treatment group and lactation on median days to conception

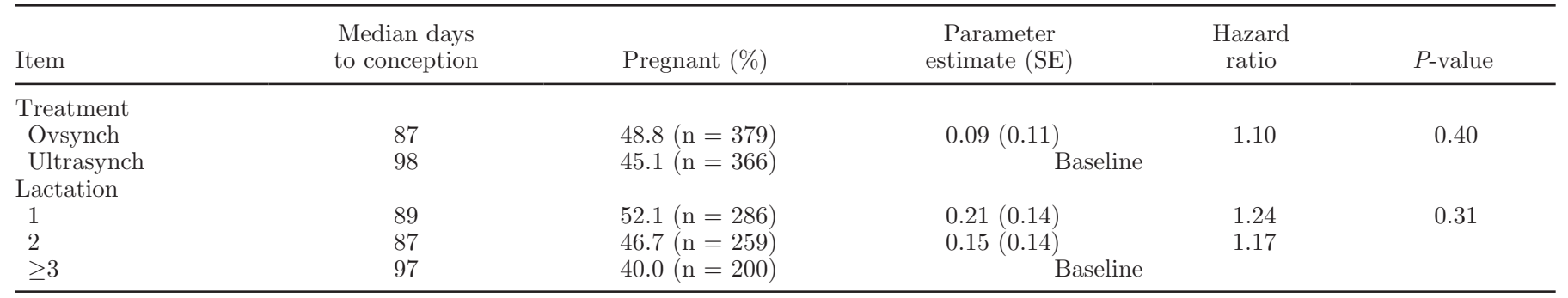


of estrus because of study design. Use of the program in a herd with better estrus detection would, in theory, produce superior results.

Another possible effect on time to conception for cows in the Ultrasynch group was their subgroup assignment to Ultra-PGF or Ultra-Ov based on presence of a CL with diameter $>23$ or $\leq 23 \mathrm{~mm}$. These assignments were based on data from Bicalho et al. (2008), which analyzed blood progesterone concentrations and CL diameter in cows 21 and $24 \mathrm{~d}$ post-AI and found the optimal thresholds by ROC curve analysis to be $23 \mathrm{~mm}$ and 22 $\mathrm{mm}$, respectively. The cows in this study had their CL diameter and blood progesterone measurements taken at 28 to 34 DPAI, at which point ROC curve analysis found the optimal threshold measurement of $20 \mathrm{~mm}$. Had the study assigned Ultrasynch cows to Ultra-PGF or Ultra-Ov based on a $20-\mathrm{mm}$ threshold diameter, a higher percentage of cows would have been assigned to Ultra-PGF. In the study herd, this would most likely have increased the median days to conception for Ultrasynch cows. As mentioned above, median days to conception may decrease compared with Ovsynch when using a 20-mm threshold diameter in a herd with a higher rate of detection of estrus.

Differences in conception data for Ultra-PGF and Ultra-Ov cows cannot be interpreted because of the study design. Cows enrolled in Ultra-PGF and that were not detected in estrus within $14 \mathrm{~d}$ or did not become pregnant were reassigned to the appropriate Ultrasynch subgroup based on CL diameter. Thus, a cow could oscillate between Ultra-PGF and Ultra-Ov multiple times during the trial if she was found nonpregnant repeatedly or was not detected in estrus. Because of this potential switching between subgroups by any given cow, a time at risk cannot be established and the 2 subgroups cannot be compared with each other or compared individually with cows in the Ovsynch group.

Economically, the Ultrasynch management program was less expensive than the Ovsynch program. With a herd estrus detection rate of $49 \%$, cows in the Ultrasynch group were palpated a total of 659 times and received $659 \mathrm{PGF}_{2 \alpha}$ and $748 \mathrm{GnRH}$ injections; cows in the Ovsynch group were palpated a total of 586 times and received $586 \mathrm{PGF}_{2 \alpha}$ and $1,172 \mathrm{GnRH}$ injections. Use of Ultrasynch in a herd with a greater estrus detection rate would result in a shorter time to conception for cows in the Ultra-PGF group, decreasing the need for repeated palpations and hormonal injections and further decreasing reproductive management costs.

These observations suggest that the use of a synchronization program based on functionality of the CL, defined by a threshold diameter of $23 \mathrm{~mm}$, was as effective as a traditional Ovsynch program. In herds with estrus detection $>50 \%$, the Ultrasynch management program may be a viable alternative to Ovsynch, with an additional benefit of having lower costs. However, the use of a threshold diameter of $20 \mathrm{~mm}$ may provide different results. In addition, better performance of such a program may be achievable on a herd with a high rate of estrus detection.

\section{ACKNOWLEDGMENTS}

The authors thank Cornell University College of Veterinary Medicine (Ithaca, NY) for generously providing support for this research through the Dean's Fund for Clinical Excellence and the owners of the collaborating dairy for allowing us access to their cows and facilities to conduct this research.

\section{REFERENCES}

Archbald, L. F., C. Risco, P. Chavatte, S. Constant, T. Tran, E. Klapstein, and J. Elliot. 1993. Estrus and pregnancy rate of dairy cows given one or two doses of prostaglandin $\mathrm{F}_{2 \alpha} 8$ or 24 hours apart. Theriogenology 40:873-884.

Bartolome, J. A., A. Sozzi, J. McHale, P. Melendez, A. C. Arteche, F. T. Silvestre, D. Kelbert, K. Swift, L. F. Archbald, and W. W. Thatcher. 2005. Resynchronization of ovulation and timed insemination in lactating dairy cows, II: Assigning protocols according to stages of the estrous cycle, or presence of ovarian cysts or anestrus. Theriogenology 63:1628-1642.

Bicalho, R. C., S. H. Cheong, L. D. Warnick, and C. L. Guard. 2007. Evaluation of progesterone supplementation in a prostaglandin $\mathrm{F}_{2 \alpha}$-based presynchronization protocol before timed insemination. J. Dairy Sci. 90:1193-1200.

Bicalho, R. C., K. N. Galvao, C. L. Guard, and J. E. Santos. 2008. Optimizing the accuracy of detecting a functional corpus luteum in dairy cows. Theriogenology 70:199-207.

Britt, J. H. 1985. Enhanced reproduction and its economic implications. J. Dairy Sci. 68:1585-1592.

Cairoli, F., A. Mollo, M. C. Veronesi, B. Renaville, M. Faustini, and M. Battocchio. 2006. Comparison between cloprostenol-induced and spontaneous oestrus fertility in dairy cows. Reprod. Domest. Anim. 41:175-179.

Caraviello, D. Z., K. A. Weigel, P. M. Fricke, M. C. Wiltbank, M. J. Florent, N. B. Cook, K. V. Nordlund, N. R. Zwald, and C. L. Rawson. 2006. Survey of management practices on reproductive performance of dairy cattle on large US commercial farms. J. Dairy Sci. 89:4723-4735.

De Vries, A. 2006. Economic value of pregnancy in dairy cattle. J. Dairy Sci. 89:3876-3885.

Fricke, P. M. 2002. Scanning the future-Ultrasonography as a reproductive management tool for dairy cattle. J. Dairy Sci. 85:1918-1926.

Fricke, P. M., D. Z. Caraviello, K. A. Weigel, and M. L. Welle. 2003. Fertility of dairy cows after resynchronization of ovulation at three intervals following first timed insemination. J. Dairy Sci. 86:3941-3950.

Galvão, K. N., M. F. Sá Filho, and J. E. Santos. 2007. Reducing the interval from presynchronization to initiation of timed artificial insemination improves fertility in dairy cows. J. Dairy Sci. 90:4212-4218.

Groenendaal, H., D. T. Galligan, and H. A. Mulder. 2004. An economic spreadsheet model to determine optimal breeding and replacement decisions for dairy cattle. J. Dairy Sci. 87:2146-2157.

Lopez, H., F. D. Kanitz, V. R. Moreira, M. C. Wiltbank, and L. D. Satter. 2004. Effect of dietary phosphorus on performance of lactating dairy cows: Milk production and cow health. J. Dairy Sci. $87: 139-145$. 
Lòpez-Gatius, F., K. Murugavel, P. Santolaria, M. Lopez-Bejar, and J. L. Yaniz. 2004. Pregnancy rate after timed artificial insemination in early post-partum dairy cows after ovsynch or specific synchronization protocols. J. Vet. Med. A Physiol. Pathol. Clin. Med. 51:33-38.

Lucy, M. C. 2001. Reproductive loss in high-producing dairy cattle: Where will it end? J. Dairy Sci. 84:1277-1293.

Lucy, M. C. 2007. Fertility in high-producing dairy cows: Reasons for decline and corrective strategies for sustainable improvement. Soc. Reprod. Fertil. Suppl. 64:237-254.

McDougall, S. 2003. Resynchrony of previously anoestrous cows and treatment of cows not detected in oestrus that had a palpable corpus luteum with prostaglandin $\mathrm{F}_{2 \alpha}$. N. Z. Vet. J. 51:117-124.

McDougall, S., and F. M. Rhodes. 1999. Detection of a corpus luteum in apparently anoestrous cows by manual palpation, transrectal ultrasonography and plasma progesterone concentration. N. Z. Vet. J. $47: 47-52$.

Meadows, C. . P. J. Rajala-Schultz, and G. S. Frazer. 2005. A spreadsheet-based model demonstrating the nonuniform economic effects of varying reproductive performance in Ohio dairy herds. J. Dairy Sci. 88:1244-1254.

Moreira, F., C. Orlandi, C. A. Risco, R. Mattos, F. Lopes, and W. W. Thatcher. 2001. Effects of presynchronization and bovine somatotropin on pregnancy rates to a timed artificial insemination protocol in lactating dairy cows. J. Dairy Sci. 84:1646-1659.

NRC. 2001. Nutrient Requirements of Dairy Cattle. 7th rev. ed. Natl. Acad. Press, Washington, DC.

Plaizier, J. C., G. J. King, J. C. Dekkers, and K. Lissemore. 1997. Estimation of economic values of indices for reproductive performance in dairy herds using computer simulation. J. Dairy Sci. 80:2775-2783.

Pursley, J. R., M. R. Kosorok, and M. C. Wiltbank. 1997. Reproductive management of lactating dairy cows using synchronization of ovulation. J. Dairy Sci. 80:301-306.

Pursley, J. R., M. O. Mee, and M. C. Wiltbank. 1995. Synchronization of ovulation in dairy cows using $\mathrm{PGF}_{2 \alpha}$ and $\mathrm{GnRH}$. Theriogenology 44:915-923.

Stevens, R. D., B. E. Seguin, and H. W. Momont. 1993. Simultaneous injection of $\mathrm{PGF}_{2 \alpha}$ and $\mathrm{GnRH}$ into diestrous dairy cows delays return to estrus. Theriogenology 39:373-380.

Stevenson, J. S., J. A. Cartmill, B. A. Hensley, and S. Z. El-Zarkouny. 2003. Conception rates of dairy cows following early not-pregnant diagnosis by ultrasonography and subsequent treatments with shortened Ovsynch protocol. Theriogenology 60:475-483. 